\title{
Psychotherapy Intervention for Narcissistic Abuse
}

\author{
Hirani D* \\ Chartered Clinical Psychologist, Private Practice in London, UK
}

\section{Opinion}

Narcissistic abuse is described as a hypernym for the psychological, financial, sexual and/or physical abuse of others by someone with narcissistic traits. This rather accurate and factual description fails to capture the anxiety, depression, terror, isolation and often paralytic hopelessness that clients I work with experience as a result of narcissistic abuse.

Be it in the workplace, family or intimate relationships, the lockdowns imposed due to the COVID pandemic appear to have worsened the trauma experienced by victims of narcissistic abuse. I have started to see a wide range of clients who present with complex post-traumatic stress symptomsin my private practice as a result of narcissistic abuse.

In my experience the best outcomes clients have obtained has been, when in addition to psychoeducation, I have put in a healthy dose of Acceptance and Commitment Therapy (ACT) with mindfulness, Compassion Focused Therapy (CFT), Cognitive Behavioural Therapy (CBT), Eye Movement Desensitisation Reprocessing (EMDR) and Solution Focused Therapy. This has helped clients make sense of what they have or are going through, increase their insight and awareness, give them answers of how they got there in the first place and what they can do to free themselves of these debilitating and 'spirit sucking' combination of symptoms.

I have the utmost compassion and empathy for anyone who has suffered narcissistic abuse. It may seem like there is no way out of the nightmarish labyrinth of narcissistic abuse. However, there is a way. It is important that clients can have confidence in knowing that there is help out there within a psychotherapeutic community that understands and validates their experience whilst being able to enable them to carve a path that can take them towards freedom. Freedom from narcissistic abuse.

\section{Acknowledgments}

None.

Funding

None.

\section{Conflicts of interest}

Author declares that there is no conflict of interest.

\begin{tabular}{|l|l|}
\hline \hline Quick Response Code: & *Corresponding author: Daksha Hirani DClinPsy, Chartered Clinical Psychologist, Private \\
Practice in London, UK \\
Received: 24 March, 2021 & Published: 01 April, 2021 \\
\hline
\end{tabular}

